\title{
A IMPORTÂNCIA DA INCLUSÃO DOS ALUNOS COM ALTAS HABILIDADES/SUPERDOTAÇÃO: UM OLHAR A PARTIR DOS ESTÁGIOS SUPERVISIONADOS
}

Joice Cristina Aparecida Cardoso ${ }^{1}$, Marielle Mielo de Souza ${ }^{1}$, Luana Pazian ${ }^{1}$, Maria Aparecida Alves Cardoso $^{1}$, Érica dos Santos ${ }^{1}$, Pâmela Suelen Barroso Carvalho ${ }^{1}$ e Mariane Della Coletta Savioli Garzotti de Araujo².

${ }^{1}$ Faculdade de Ciências e Tecnologia de Birigui - FATEB, Curso de Pedagogia, Birirgui, SP. ${ }^{2}$ Universidade do Oeste Paulista - UNOESTE, Mestrado em Educação, Presidente Prudente, SP. E-mail: joice.cardoso2015.jc22@gmail.com

\section{RESUMO}

O artigo emergiu a partir de uma pesquisa realizada na área de educação especial inclusiva desenvolvida na disciplina de Fundamentos da Educação dos Portadores de Necessidades Especiais, no quinto semestre do Curso de Licenciatura em Pedagogia de uma faculdade do interior paulista. Visou pesquisar quem são e como desenvolver o trabalho pedagógico significativo segundo a as políticas de Educação Especial Inclusiva para os alunos que possuem Altas Habilidades/Superdotação. A metodologia da pesquisa é qualitativa a partir das observações ocorridas por meio dos estágios supervisionados e observações de atendimentos educacionais especializados e de pesquisas anteriores a esse assunto. Os resultados da pesquisa mostram que as escolas ainda se encontram pouco preparadas para detectar esses alunos, além da necessidade de capacitação de professores para uma prática pedagógica adequada. Conclui-se que a criança superdotada precisa de uma real integração com outros grupos sociais, bem como de um trabalho colaborativo entre: família, escola e sociedade, estabelecendo parcerias com outros profissionais a fim de desenvolver o potencial desse alunado.

Palavras-Chave: Altas habilidades, Superdotação, Inclusão.

\section{THE IMPORTANCE OF THE INCLUSION OF STUDENTS WITH HIGH SKILLS/GIFTED: A LOOK FROM THE STAGES SUPERVISED}

\begin{abstract}
The article has emerged from a survey conducted in the area of special education inclusive developed in the discipline of Foundations of Education of people with special needs, in the fifth semester of the course degree in Pedagogy from a college in the interior of São Paulo. Was searching for who they are and how to develop the pedagogical work meaningful according to the policies of Special Education inclusive for students who have high skills/Gifted. The research methodology is qualitative from the observations occurred through the supervised and observations of specialized educational and research prior to this subject. The survey results show that schools are still little prepared to detect these students, in addition to the need for training teachers for a pedagogical practice. It is concluded that the child superdotada needs a real integration with other social groups, as well as a collaborative work between: family, school and society, establishing partnerships with other professionals in order to develop the potential of the students.
\end{abstract}

Keywords: High skills, gifted, Inclusion. 


\section{INTRODUÇÃO}

Com o avanço da educação, principalmente na perspectiva da educação inclusiva novas maneiras de pensar e enxergar a educação de pessoas com deficiências começam a se transformar, visto que há muito tempo as escolas enxergavam os alunos de uma maneira errônea na qual os segregavam, classificavam e diferenciavam um dos outros, estereotipando modelos e perfis. Essas escolas eram consideradas as escolas dos diferentes.

Nesses modelos e perfis se enquadravam os ditos "normais" e "especiais", no qual os ditos "normais" eram os alunos de escola regular e que eram aceitos pela sociedade e os "especiais" eram os vistos negativamente, distintos dos parâmetros aceitos.

Essas instituições educacionais excludentes opuseram-se as mudanças e propostas que estavam sendo feitas, pois haviam classificações, rotulações, seguidos de aparatos pedagógicos que fizeram inclusões e exclusões aos alunos do espaço escolar.

A escola inclusiva é considerada a escola das diferenças, surge quebrando essas barreiras, modelos e perfis, que por muito tempo foram idealizados aos alunos, redefinindo esses preceitos e questionando-os, acabando com as rotulações e valorizando as diferenças.

Esse poder que define a identidade normal, detido por professores e gestores mais próximos ou mais distantes das escolas, perde a sua força diante dos princípios educacionais inclusivos, nos quais a identidade não é entendida, como natural, estável, permanente, acabada, homogênea, generalizada, universal. Na perspectiva da inclusão escolar as identidades são transitórias, instáveis, inacabadas e, portanto, os alunos não são categorizáveis, não podem ser reunidos e fixados em categorias, grupos, conjuntos, que se definem por certas características arbitrariamente escolhidas. (BRASIL, 2010, p. 7)

Deve ser questionado com constância o modelo de escola excludente que extirpa o direito de todos ao ensino.

As instituições educacionais devem ser um lugar de todos, que valorizem as diferenças, capacidades e as desenvolvem, tornando cidadãos com participações ativas no processo de ensino- aprendizagem, com direitos e deveres, sendo respeitados em todos os aspectos.

Ao indagar e contrapor-se as práticas pedagógicas aplicadas com intuito de segregação e exclusão, inicia-se a inserção de práticas que agreguem, significados, valorizando, oportunizando e capacitando a todos em suas diferenças e dificuldades.

Para que haja mudanças, a escola deve repensar sua gestão, para uma gestão democrática, no qual todos participem. Levando em consideração todos os aspectos escolares, como horários, formação docente, materiais pedagógicos e administrativos entre outros, contribuindo para um melhor processo de ensino- aprendizagem.

Para que se atenda as mudanças e necessidades da instituição educacional, precisa- se estar presente no Projeto Político Pedagógico da escola, o PPP.

O PPP é um documento administrativo e pedagógico, a qual é elaborado pelo gestor com colaboração de todo o segmento escolar. Este não deve ser algo paralelo, mas sim, integrado na realidade da instituição.

No PPP deve conter todos os caminhos a percorrer durante o ano letivo, juntamente com propostas, por meio de estudos, para a formação de cidadãos que almeja obter, sempre observando o perfil de demanda local.

Ao sistematizar estas escolhas e decisões, o PPP, a partir de um estudo da demanda da realidade escolar cria as condições necessárias para a elaboração do planejamento e o desenvolvimento do trabalho da sua 
equipe e da avaliação processual das etapas e metas propostas. (BRASIL, 2010, p. 11)

Os professores por sua vez, alcançam a democracia e mudanças por meio de seu trabalho em salas de aula, ensinando a todos sem discriminação, de maneira diversificada na qual respeite as particularidades dos alunos, os fazendo evoluir conforme suas capacidades. "O professor, então, desempenhará o seu papel formador, que não se restringe a ensinar somente a uma parcela dos alunos que conseguem atingir o desempenho exemplar esperado pela escola. Ele ensina a todos, indistintamente." (BRASIL, 2010, p. 14).

Por meio dessas mudanças a Política Nacional de Educação Especial na Perspectiva da Educação Inclusiva (2008) viabilizou o Atendimento Educacional Especializado (AEE), no qual são salas próprias para esse atendimento denominada Salas de Recursos Multifuncionais, que complementa e/ou suplementa a sala regular oferecendo ao aluno atendido mais autonomia dentro ou fora da escola. O AEE utiliza recursos pedagógicos acessíveis e adaptados (se necessário), sendo um atendimento obrigatório no sistema de ensino.

Dentre alguns alunos público alvo da Educação Especial atendidos segundo a Política Nacional de Educação Especial na Perspectiva da Educação Inclusiva, estão os alunos com Altas Habilidades e Superdotação, na qual são indivíduos que apresentam um potencial acima da média em diversas áreas podendo ser ela isoladas ou combinadas. Essas áreas são: "[...] intelectual, acadêmica, liderança, psicomotricidade e artes. Também apresentam elevada criatividade, grande envolvimento na aprendizagem e realização de tarefas em áreas de seu interesse. " (MEC/SEESP, 2008).

Vale ressaltar que pessoas que possuem Altas Habilidades e Superdotação, não são indivíduos que possuem alguma deficiência, mas sim, pessoas que como dito anteriormente, apresentam potencial acima da média em áreas isoladas ou combinadas, na qual a classe regular não supre suas necessidades em relação ao ensino e aprendizagem, sendo necessário que haja algo que suplemente esse ensino, possibilitando um maior desenvolvimento, aprimoramento e aproveitamento de suas capacidades.

Em estágio supervisionado e diálogo com professores de AEE, foi possível constatar que as "Altas Habilidades" pode ocorrer de forma isolada em ou outra área do desenvolvimento humano (intelectual, artística, liderança etc.). Já a "Superdotação" está relacionada a um nível de QI (quociente intelectual acima da média) e notável desempenho em diferentes áreas da atuação humana.

Para se ingressar no $\mathrm{AEE}$, basta estar regularmente matriculado na escola comum a qual o aluno frequenta. Normalmente, os alunos com Altas Habilidades e Superdotação não enfrentam problemas ao ingressar na escola comum. Como muitas crianças com deficiências enfrentam, que por conta de suas limitações encontram lugares inacessíveis, dificultando suas permanências no local.

O AEE é previsto por lei, podendo ser garantido tanto pela rede pública ou privada.

Tais centros, contudo, devem estar de acordo com as orientações da Política Nacional de Educação Especial na Perspectiva da Educação Inclusiva (2008) e com as Diretrizes Operacionais de Educação Especial para o Atendimento Educacional Especializado na Educação Básica (MEC/ SEESP, 2009).

Segundo MEC (2010, p. 18), há motivos para que haja esse atendimento preferencialmente na escola regular, como afirma o supracitado:

O motivo principal de o AEE ser realizado na própria escola do aluno está na possibilidade de que suas necessidades educacionais específicas possam ser atendidas e discutidas no dia a dia escolar e com todos os que atuam no ensino regular e/ ou na educação especial, aproximando esses alunos 
dos ambientes de formação comum a todos. Para os pais, quando o $A E E$ ocorre nessas circunstâncias, propicia-Ihes viver uma experiência inclusiva de desenvolvimento e de escolarização de seus filhos, sem ter de recorrer a atendimento exteriores à escola. (MEC, 2010, p. 18).

Entretanto, o AEE é assegurando mesmo não existindo a sala de recursos multifuncional na escola em que o aluno estuda, portanto,

[...] nos casos de não existir a sala de recursos multifuncionais na escola em que o aluno estuda, este último deve ir à escola mais próxima que possui o atendimento, em horário oposto, utilizando-se de um meio de transporte e com consentimento dos responsáveis. Este deve estar registrado no PPP da escola. (MEC, 2010, p. 20).

É muito importante que os alunos que necessitem do Atendimento Educacional Especializado não sejam vistos como somente do professor responsável por este atendimento.

Ele é um aluno de todos da escola e toda esta deve estar envolvida na formação e capacitação desse aluno. Como também o profissional do Atendimento Educacional Especializado deve estar inserido e acompanhar os processos pedagógicos e burocráticos da escola em relação aos alunos, sendo visto como mais um componente do ambiente escolar.

É de suma importância a articulação entre o professor do AEE e o ensino regular. Pois, é por meio dessa articulação que o primeiro acompanha o desenvolvimento e as dificuldades se seu aluno.

O profissional do AEE em relação aos alunos com Altas Habilidades e Superdotação, deve não só ter articulações com o professor regular, como também com profissionais de diversas áreas, a qual instigará os discentes a buscar mais desenvolvimento e aprimoramento em suas áreas de domínio. O professor do Atendimento Educacional Especializado deve também se articular com a família e comunidade para colher informações sobre a criança, obtendo um retorno de seu trabalho e assim utilizar seus recursos de forma a compreender melhor as necessidades de seus alunos.

Esse profissional de AEE deve possuir formação específica para atuar, sempre com atualizações para ampliação de seus conhecimentos. Deve utilizar em seus atendimentos uma metodologia que faça o aluno se tornar ativo, instigando-o sempre a pensar e questionar, construindo seus conhecimentos, visando um atendimento de qualidade.

Em busca de defender positivamente a importância de um trabalho em conjunto, que visa o pleno desenvolvimento de alunos considerados superdotados, levando em consideração a relevância da escola, família, rede multidisciplinar entre outros, no qual enfatiza que estes não estão no vazio, o modelo Triádico da teoria de Renzulli (2004) demostra que o trabalho em equipe promove o e amplia o conhecimento do aluno de forma equilibrada.

Os objetivos específicos desse estudo foram: Maximizar a participação do aluno na classe comum do ensino regular, beneficiando-se da interação do contexto escolar, bem como, potencializar a(s) habilidade(s) demonstrada(s) pelo aluno, por meio do enriquecimento curricular no plano de atendimento individual; Expandir o acesso do aluno a recursos de tecnologia, matérias pedagógicos e bibliográficos de sua área de interesse, também promover a participação do aluno em atividades voltadas à prática da pesquisa e desenvolvimento de produtos, e estimular a proposição de o desenvolvimento de projetos de trabalho no âmbito da escola, com temáticas diversificadas, como artes, esporte, ciências e outras. 


\section{METODOLOGIA}

A metodologia da pesquisa é qualitativa por meio da observação ocorrida durante os estágios supervisionados realizados pelas autoras do artigo, no decorrer do curso de Licenciatura em Pedagogia, entre os anos de 2016 e 2017, nas escolas municipais o interior do noroeste paulista. Para Minayo (2001), é qualitativa com observações ocorridas por meio dos estágios supervisionados nas escolas, e dos atendimentos educacionais especializados, além do estudo de pesquisas anteriores a esse assunto.

Análise dos resultados da pesquisa preveem que as escolas ainda se encontram pouco preparadas para detectar esse alunado, além de constatar que professores em sala de aula do ensino regular, professor do AEE e demais parceiros da sociedade, devem sempre trabalhar em colaboração para oferecer propostas, intervenções pedagógicas e recursos que visem estimular o aluno com superdotação/ altas habilidades, bem como propor articulações em diversas áreas que suplementam a proposta curricular.

\section{RESULTADOS}

Os resultados da pesquisa, segundo a observação a partir dos estágios supervisionados e por meio da observação dos trabalhos do AEE nas escolas municipais da região, detectam a falta de preparo das escolas e dos professores principalmente com relação ao desenvolvimento do trabalho pedagógico e motivador dos alunos com altas habilidades/ superdotação.

Observou-se também, que professores e escolas também não conseguem subsídios para detectar esses alunos, o que implica na falta de propostas pedagógicas adequadas a esse público alvo.

Nos diálogos com os professores especialistas de AEE, durante os estágios supervisionados, os estudantes do curso de Licenciatura em Pedagogia, puderam constatar que não há certeza quanto a informações sobre a existência do aluno superdotado nas escolas, e que os sistemas municipais públicos da região estão em fase de elaboração de um protocolo para investigação de possíveis caso.

Observou-se também que no caso de existirem posteriormente esses casos, a legislação educacional prevê a possibilidade de aceleração para os casos em que o aluno apresente desempenho e capacidade tais que the garantam o direito de cursar uma série/ano escolar subsequente (avançar).

Os alunos com Altas Habilidades/ Superdotação estão incluídos no público Alvo do AEE, pois a Política Educacional para a Educação Inclusiva e dispositivos legais (Resolução do Conselho Nacional de Educação para o AEE) incluem esses alunos dentre o público- alvo do AEE, visando estimular o desenvolvimento de seu potencial.

\section{DISCUSSÃO}

De acordo com os pressupostos de Piaget, entende-se que desenvolvimento e a aprendizagem se dá a partir da interação do sujeito com o meio, que ocorre no processo de desiquilíbrio/reequilibração, permitindo a assimilação do conhecimento e aprendizagem. A pesquisa realizada traz como análise também as questões educacionais referentes as possíveis potencialidades elevadas de indivíduos que apresentam as características desse público que é alvo da Educação Especial Inclusiva, podendo ser isoladas ou combinadas, embasados em pesquisas piagetianas sobre os esquemas cerebrais, e também de acordo com outros pesquisadores na qual apontam diferenças anatômicas cerebrais entre alunos ditas normais em relação as consideradas superdotadas ou com altas habilidades.

Tal processo ocorre a partir dos estímulos do meio denominados "motivações", no qual os neurônios trabalham entre si. Piaget enfatiza que esses esquemas não acontecem apenas em pessoas com Altas Habilidades/Superdotação, mas em pessoas também ditas normais, porém em 
Altas Habilidades/Superdotação os choques (sinapses) são mais intensos (sensibilidade) havendo o desequilíbrio e, em seguida assimilação, ocasionando a reequilibrarão, acomodação e a autorregularão, tornando o indivíduo mais competente.

De acordo com a observação dos estágios supervisionados e o contato com o Atendimento Educacional Especializado, verificou-se que o desenvolvimento e aprendizagem de alunos com Altas Habilidades e Superdotação há diferença. São alunos que apresentam um desempenho acima da média, na qual pode ser habilidades isoladas ou combinadas.

Entende-se que mesmo sendo algo biológico, é necessários estímulos externos que derivam de todas as partes como: sociedade, família, escola e o Atendimento Educacional Especializado, configurando um trabalhado em forma de rede e multidisciplinar. Esse trabalho deve acontecer por meio de uma relação de apoio entre a sala de aula regular e o AEE, identificando os alunos que precisam de atendimento, desenvolvendo um trabalho de qualidade embasados em conceitos de práticas pedagógicas inclusivas, definindo as diretrizes e estratégias que busquem desenvolver habilidades dos alunos em questão.

Em algumas redes municípios da região do noroeste paulista, o Planejamento Político Pedagógico das escolas já prevê articulações com o Ensino Superior, com intuito de desenvolver pesquisas em Educação Especial Inclusiva, bem como nas áreas de Artes, Esportes, entre outras, a fim de promover enriquecimento, mais estímulos e valorização de suas diferenças.

É, segundo as observações, averiguado que os possíveis resultados das avaliações, tendo sido analisado não apenas o que o aluno aprendeu, mas visando buscar resultados que possibilitem ir além, problematizar os processos de ensino e aprendizagem e identificar diferentes formas de construir o aprendizado.

Para haver um bom desenvolvimento dos potenciais dos alunos com altas habilidades/ superdotação, devem ser desenvolvidos de forma colaborativa, os projetos de trabalho com o intuito de instigar a aprendizagem, inter-relacionando diferentes temáticas, partindo dos interesses dos alunos e proporcionando aprofundamento nos temas.

De acordo com a teoria do modelo Triádico de Renzulli (2004), que defende que o aluno superdotado e com altas habilidades não está no vazio, mas envolvido em vários outros componentes, no qual deve ser trabalhado os aspectos pessoais do mesmo, promover o envolvimento da família, escola e sociedade, tudo em prol do desenvolvimento uniforme e equilibrado.

Veja o modelo Triádico de Renzulli:

Figura 1. Modelo Triádico da teoria de Renzulli.

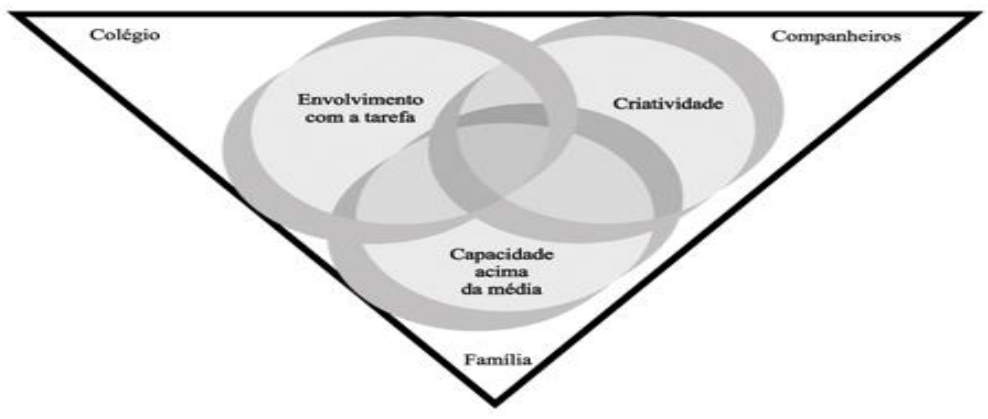

Fonte: Renzulli $(1978,1986)^{1}$

O modelo Tríadico da Superdotação, segundo a Teoria de Renzulli (2004), é uma confluência de três fatores que são colocados como se fossem anéis interligados, por esse aluno possuir habilidades maiores referentes a outra criança da mesma faixa etária, essas habilidades

\footnotetext{
${ }^{1}$ Modelo Tríadico de Renzulli. Fonte disponível em: http://www.scielo.br/scielo.php?script=sci_arttext\&pid=S0104- 40362007000400003
} 
que a fazem se destacar no momento de desenvolver as diversas atividades dentro de sala de aula, além de apresentar um maior envolvimento com as tarefas, também se destacam pela persistência, atenção e dedicação integral durante a realização de algo, principalmente se este despertar seu interesse.

Como são concentrados e criativos gostam de solucionar problemas de formas diferentes, por esse motivo a escola precisa aproveitar e exercer a articulação entre os componentes, que esteja configurado em uma relação de apoio, embasados em conceitos e em práticas pedagógicas inclusivas, capaz de desenvolver projetos consistentes, para potencializar as habilidades, a criatividade e o total envolvimento deste aluno.

Segundo Brasil (1999), esse alunado se encontra apto e disposto a aprender e por esse motivo, educadores devem estar atentos e preparados para perceber possíveis indícios, a partir de atitudes e características apresentadas pelo aluno. Verificou-se que o Superdotado possui características inatas e que influencias recebidas por parte da família, professores e o meio circundante ajudará revelar, desenvolver e ampliar seu potencial, autoestima, saúde e determinará sua personalidade, principalmente sua valorização e habilidades motores, cognitivas e psicológicas.

As características do Superdotado que os difere dos demais alunos é fato de possuir maior facilidade de aprendizagem, raciocínio rápido, além de ter uma postura crítica e questionadora em relação aos conceitos e conteúdos apresentados pelo educador, bem como não reconhecer a função da escola e do professor ao se nivelar a ele. Contudo, o Superdotado apresenta independência no trabalho, desempenho acima da média, precocidade, velocidade e ritmo de aprendizagem próprio, alto grau de concentração e envolvimento com a tarefa, por esse motivo são considerados prodígios.

Desenvolver-se como ser humano é papel do aluno. Favorecer o pleno desenvolvimento, a ação educativa, ampliar fronteiras, respeitar a diversidade é papel do educador. Todo o processo de evolução baseia-se na essência do conhecimento da natureza humana, desse ser universal. (BRASIL, 1999, p.24).

Estudiosos e especialistas apresentam divergências em relação a Nomenclatura, no qual o assunto se constitui como fonte polemica, sendo nomeada de forma diferente, o Conselho Europeu nomeia como "Altas Habilidades", o Conselho Mundial nomeia como "Superdotação ou Talentos". Sendo assim, Altas Habilidades referem-se aos traços consistentes superiores, que em qualquer campo do saber ou do fazer permanece com frequência e duração no repertório dos comportamentos da pessoa, observáveis nas ações, no fazer, no pensar e expressados em diferentes formas como no gestual, área intelectual, plástica, teatral, matemática musical, entre outras.

Os classificados como Superdotados e Talentosos são considerados indivíduos com habilidades evidentes e com alto desempenho. De acordo com o MEC, os superdotados se enquadram tradicionalmente entre vários tipos de superdotação como: o tipo individual, tipo social, tipo acadêmico, criativo, talentos especiais, etc..., nas quais fazem transparecer cada um dos potenciais e singularidades correspondentes a cada tipo de superdotação.

No entanto, devemos considerar que nem todos os alunos com Altas Habilidades ou Superdotado e Talentosos apresentam as mesmas características e potencialidades, devido suas singularidades, fatos que evidenciam a necessidade de receberem atendimento especial, por causa das dificuldades adaptativas e os sentimentos de rejeição e de discriminação por parte de colegas e professores.

Com base em análises, o MEC defende uma filosofia inclusiva propondo integrar o aluno com necessidades especiais no sistema escolar e com outras áreas que trabalhem questões 
relacionadas à saúde, ação social, disporto e trabalho, a fim de promover a integração social, objetivar o ajustamento de cada indivíduo com o ambiente social, o acesso e a conquista de seu espaço.

Entretanto, o que se pretende é de fazer deste, um agente de transformação social, usufruindo de sua inteligência e potencialidades a favor da humanidade. Mas para que isso ocorra, é necessário à articulação e o preparo da família, escola, profissionais da educação, especialistas e estudiosos, para poder e saber lidar com essas pessoas tão capazes, a fim de nortearem da melhor forma suas ações para bons resultados no futuro.

O processo de assistência ao superdotado e talentoso não deverá ser modelado por um sistema, como processo a ser desenvolvido, mas ser colocado como uma filosofia de trabalho a ser perseguida. Devido à natureza peculiar de cada ser humano desse segmento, é preciso que sua inserção social seja vista, não sob o ângulo de um ser humano e uma comunidade, mas de um ser humano cuja capacidade o coloca como agente de transformação, cuja jornada é descobrir quais são suas possibilidades, seus produtos e em que patamar se coloca no nível de produção e com o que contribui socialmente em nível de novo e de qualidade universal. (BRASIL, 1999, p. 60).

No que tange o trabalho colaborativo e a necessidade de apoio educacional, orientações e avaliações que detectem o alunado específico, Capellinni, Zanata e Pereira (2010), corroboram que a maioria dos professores sonha em trabalhar em equipe com apoio, de modo a compartilhar certezas e dúvidas e vivenciar momentos de trocas de experiências. Estas trocas enriquecem o trabalho do docente, trazem confiança e dão aos professores a condição de serem atores da própria prática pedagógica de forma colaborativa, não de forma isolada.

Colaboração é a contribuição e interação entre indivíduos, que se unem em prol de um objetivo/desafio comum. O ambiente escolar segue a mesma linha, com a otimização do trabalho do professor e aprendizagem dos alunos. A colaboração deve ser vista como uma estratégia de trabalho pedagógico para se alcançar objetivos que, isoladamente, não seriam atingidos ou seriam mais difíceis de serem alcançados. Os desafios da escola somente serão suportados através da colaboração. (CAPELLINNI, ZANATA e PEREIRA, 2010).

Considerando que escolas refletem a sociedade na qual está inserida, dentre as diversas estratégias existentes para remover as barreiras da aprendizagem na escola, a colaboração entre educadores comuns e especialistas em Educação Especial, bem como entre equipes de consultores especialistas, ou mesmo entre os alunos, tem sido uma das ações mais significativas no processo de inclusão escolar. (CAPELLINNI, ZANATA e PEREIRA, 2010, p. 75).

A colaboração é importante para as escolas porque possibilita que cada professor, através de suas experiências, contribua para a resolução de problemas. Dentre algumas formas de trabalho coletivo, o ensino colaborativo está utilizado na parceria direta entre professores da Educação Comum e da Educação Especial, favorecendo, assim, a inclusão escolar.

De acordo Capellinni, Zanata e Pereira (2010, p. 77):

O ensino colaborativo é uma estratégia didática inclusiva em que o professor da classe comum e o professor, ou especialista planejam de forma colaborativa, procedimentos de ensino para ajudar no atendimento a estudantes com deficiência, em classes comuns, mediantes um ajuste por parte dos professores. Nesse modelo, dois ou mais professores possuindo 
habilidades de trabalho distintas, juntam-se como forma coativa e coordenada, ou seja, em um trabalho sistematizado, com funções previamente definidas para ensinar grupos heterogêneos, tanto em questões acadêmicas quanto em questões comportamentais em cenários inclusivos. Ambos compartilham a responsabilidade de planejar e de implementar o ensino e a disciplina em sala de aula.

E asseveram que (2010, p. 77-78):

O trabalho colaborativo efetivo requer compromisso, apoio mútuo, respeito, flexibilidade e uma partilha dos saberes. Ninguém deve considerar-se melhor que outros. Cada profissional envolvido pode aprender e beneficiar-se dos saberes dos demais e, com isso, o beneficiário maior será sempre o aluno.

Para o desenvolvimento das práticas colaborativas, ambos os professores devem conhecer todo o currículo e desenvolver o planejamento em conjunto. Juntar dois professores na mesma sala pode não ser fácil, especialmente porque estes são formados para conduzir o ensino de modo autônomo, é uma profissão tradicionalmente individual. Para desenvolverem práticas inclusivas e colaborativas, os professores para devem compartilhar metas, decisões, responsabilidades, avaliação e administração da sala, devem considerar a classe como "nossa" e não como "minha". (CAPELLINNI, ZANATA e PEREIRA, 2010).

O ensino colaborativo pode ocorrer de diversos modos. Gargiulo (2003) sugere cinco propostas, a saber: um professor como suporte, estações de ensino, ensino paralelo, ensino alternativo e equipe de ensino. A proposta escolhida depende das características e necessidades do grupo de alunos, da demanda escolar, da experiência e preferência do professor, do espaço e do tempo disponíveis.

Referente a um professor como suporte, o professor da Educação Comum e o da Especial atuaram juntos em sala de aula, porém apenas um apresentará as instruções, enquanto o outro apoiará os estudantes. Quanto às estações de ensino, serão criados ambientes na sala para a divisão de diversas partes da atividade; cada estação corresponderá a uma atividade que deverá ser desenvolvida pelos grupos criados. No ensino paralelo, a instrução será articulada e cada professor ficará responsável por $50 \%$ do grupo de alunos. No ensino alternativo, um professor apresenta as instruções a um grande grupo de alunos, enquanto o outro interagirá com um pequeno grupo. A equipe de ensino e o ensino coorporativo ou interativo, onde cada professor dará igualmente suas instruções. (GARGIULO, 2003).

Preceituam Capellinni, Zanata e Pereira (2010), a colaboração é importante porque dá a oportunidade de ampliar o conhecimento de educadores com diferentes formações e experiências. Poucos professores tem a possibilidade de trocar experiências e muitas vezes decidem sozinhos. A aproximação com outra pessoa em sala geralmente ocorre via estágio, isso pois, o profissional em formação não confere credibilidade, ou com a participação de professor coordenador ou supervisor, pode aparentar um modo de fiscalização.

Segundo Dieker e Barnett (1996), os professores da Educação Comum e da Educação Especial devem unir seus conhecimentos e combinarem recursos para fortificar o processo de ensino aprendizagem, de modo a aprender uns com os outros e satisfazer as necessidades dos alunos. Para Wood (1998), o ensino colaborativo deve proporcionar a as estudantes tarefas apropriadas, de modo que cada um aprenda e participe do processo.

Capellinni, Zanata e Pereira (2010) asseguram que os sistemas educacionais deveriam planejar um processo de ensino colaborativo, garantindo todos os recursos disponíveis. 0 
planejamento deve ser contínuo, assim, deve apoiar as novas iniciativas e também deve permitir a revisão e ajustes com base nos progressos dos alunos.

Para as autoras (2010, p. 81-82):

O ensino colaborativo pressupõe oportunidades de desenvolvimento pessoal e profissional do professor. Por isso, motivação, compromisso pessoal e participação voluntária são ingredientes importantes para o sucesso do ensino colaborativo. Para uma colaboração efetiva é necessário: ser tolerante, reflexivo e flexível, aceitar a responsabilidade pelo sucesso de todos os alunos, manter relações positivas um com o outro e ajustar expectativas para os estudantes com deficiência a classe comum.

No trabalho de colaboração almeja-se que haja uma contrapartida de ambos os lados. Deve-se considerar que o trabalho de todos é essencial.

Os primeiros parceiros são os alunos. Eles devem ser valorizados para que reconheçam o potencial que tem nessa parceria. O professor deve estar atento às histórias narradas pelos alunos e que retratam suas experiências, deve verifica as preferências e habilidades de cada um e deve verificar como os grupos estão organizados. A organização deve consistir em um apoio mútuo, em que o aluno descubra que pode ensinar, mas também aprender com o outro. É importante que todos sempre tenham algo a ensinar e algo a aprender. (CAPELLINNI, ZANATA e PEREIRA, 2010).

Sobre as possibilidades de apoio no trabalho pedagógico com seus alunos que o professor pode unir com a equipe escolar, família e comunidade. $O$ trabalho se torna mais fácil e gratificante quando são estabelecidas parcerias.

No âmbito escolar, todos os funcionários (desde a direção até os que trabalham na limpeza) devem ser envolvidos no ensino colaborativo. Há a possibilidade de os agentes escolares (diretor, professor coordenador, professor da sala de recursos, professor da sala de apoio pedagógico especializado) auxiliarem o professor no ensino e aprendizado do aluno com deficiência. Colaboração é diferente de pena, a colaboração envolve proporcionar condições para que o aluno cresça. (CAPELLINNI, ZANATA e PEREIRA, 2010).

As colaborações não precisam ficar restritas ao pessoal da escola. Às vezes também é possível a presença de um terceiro colaborador que trabalhará em comum acordo com o professor. O professor pode estabelecer parcerias de trabalho e ter a colaboração de profissionais da área da saúde (psicólogos, terapeutas ocupacionais, pedagogos, dentre outros). (CAPELLINNI, ZANATA e PEREIRA, 2010).

\section{CONCLUSÃO}

Pode-se dizer que pessoas que possuem Altas Habilidades/ Superdotação, fazem parte do público alvo do Atendimento Educacional Especializado, pelo fato de que a sala de aula regular não suprir suas necessidades e desenvolver suas habilidades, necessitando de estímulos e orientações.

Portanto a Educação Especial na Perspectiva da Educação Inclusiva vem para potencializar as habilidades e promover um ambiente estimulador ao aluno, servindo como ponte entre escola e instituição especializada, e oferecendo também um apoio ao professor de sala de aula regular.

Contudo, o trabalho deve ser pautado numa educação que vise a formação deste Superdotado e Talentoso, dentro de um processo que almeje sua autodesenvolvimento, tornar um ser expressivo e produtivo por meio de uma assistência complementar diferenciada, que atenda o ritmo de aprendizagem do envolvido. 


\section{REFERÊNCIAS}

BRASIL. Ministério da Educação. Programa de Capacitação de Recursos Humanos do Ensino Fundamental: superdotação e talento vol. 1 fascículos V. Brasília: MEC/SEESP, 1999.

- Ministério da Educação. Política Nacional de Educação Especial na Perspectiva da Educação Inclusiva. Brasília: MEC/SEESP, 2008.

- Ministério da Educação. Secretaria de Educação Especial. Diretrizes Operacionais da Educação Especial para o Atendimento Educacional Especializado na Educação Básica. Brasília: MEC/SEESP, 2009.

. Ministério da Educação. Secretaria de Educação Especial Universidade Federal do Ceará. A Educação Especial na Perspectiva da Inclusão Escolar: A Escola Comum Inclusiva. Brasília, 2010.

. Ministério da Educação. Secretaria de Educação Especial Universidade Federal do Ceará. A Educação Especial na Perspectiva da Inclusão Escolar: Altas habilidades/ Superdotação. Brasília, 2010.

CAPELLINNI, V. L. M. F.; ZANATA, E. M.; PEREIRA, V. A. Ensino colaborativo. In: CAPELLINNI, Vera Lúcia Messias Fialho; RODRIGUES, Olga Maria Piazentin Rolim. Práticas pedagógicas inclusivas: da criatividade à valorização das diferenças. Bauru: UNESP/FC/MEC, 2010.

DIEKER, L. A.; BARNETT, C. A. Effective co-teaching. Teaching Exceptional Children. V. 29, n. 1, p.57. Interactions. White Plains, NY: Longman, 1996.

GARGIULO, R. M. Education on contemporary society: an introduction to exceptionality. Thomson Learning: United Station, 2003.

RENZULLI, J. S. O Que é Esta Coisa Chamada Superdotação, e Como a Desenvolvemos? Uma retrospectiva de vinte e cinco anos. Ano XXVII, n. 1 (52), p. 75 - 131. Porto Alegre - RS, Jan./Abr. 2004.

WOOD, M. Whose job is it anyway? Educational roles in inclusion. Exceptional Children, v. 64, n. 2, p. 181-195, 1998, https://doi.org/10.1177/001440299806400203 